\title{
El colonialismo como encubrimiento del otro
}

\author{
Rudy Montano ${ }^{1}$
}

El artículo pretende plantear una definición del encubrimiento y sus manifestaciones en tres situaciones históricas diferentes: la relación entre Europa y Oriente, la relación entre Europa y América y en la actualidad, la relación entre Estados Unidos y el mundo islámico. El punto en común de estas tres situaciones es que se usan términos optimistas para encubrir realidades de explotación, exclusión y marginación.

The article aims to establish a definition of concealment and its manifestations in three different historical situations: the relation between Europe and Eastern, the relation between Europe and America, and the present relation between the United States and Islamic world. The point in common between these three situations is that they use optimistic terms to conceal realities of exploitation and exclusion

\section{INTRODUCCIÓN}

El colonialismo fue un fenómeno que afectó a nuestros países de América de una manera vertiginosa. Y afectó tanto que todavía hoy se sienten sus efectos. Con el término colonialismo se hace referencia aquí a la situación de sometimiento y dominio que Europa manifestó frente a los países denominados pobres o tercer mundistas. Este colonialismo, a la vez tuvo diversas concreciones. Una de esas diversas concreciones que se quiere exponer en este artículo es el encubrimiento, que se concreta en el encubrimiento del Otro. Con esta expresión se quiere dar a entender lo siguiente: los países colonizadores han utilizado términos muy optimistas como descubrimiento, encuentro de dos mundos, etc., para encubrir una realidad de muerte, explotación y represión. Es, siguiendo a Enrique Dussel, no descubrir al Otro, sino en-cubrirlo con "lo mismo de Europa"2. Dicho de otra manera, Europa se descubre, se autoafirma y se autolegitima sometiendo a los Otros, haciéndolos víctimas de sus prácticas colonialistas. Esta forma concreta de colonialismo como encubrimiento se expresa de tres maneras muy particulares: la relación de Europa con Oriente, la relación de Europa con América y la relación de EE. UU. con el mundo islámico.

1 Licenciado en Teología, profesor de Teología del Nuevo Testamento, en la Universidad Don Bosco.

2 DUSSEL, E. 1492: el encubrimiento del Otro. Hacia el origen del mito de la modernidad". Ed. Plural, La Paz, 1992. En estos planteamientos, Dussel va a seguir las ideas de Charles O'Gorman que construye toda una teoría sobre la invención de las Américas. 


\section{1. ¿Por qué el encubrimiento del Otro? Justificación del tema}

Enrique Dussel, fundamentándose en los aportes de Emmanuel Levinas, reflexiona sobre el interés del Otro que está frente al Uno o lo Mismo de Europa. Con estas expresiones, se quiere afirmar que el interés fundamental de Europa se ha centrado en el sujeto-individuo, en el sujeto dominador, que quiere imponerse al Otro, quiere ocultarlo y anularlo. Es el yo-individuo propio de los sistemas capitalistas e ilustrados y cuyo interés sólo puede centrarse en lo Uno y lo Mismo. Es un planteamiento propio de lo que se denomina Modernidad. Frente a este sistema dominador, aparece la alternativa propia de la filosofía de la liberación, cuyo representante más importante es Enrique Dussel. Carlos Beorlegui plantea este interés de Enrique Dussel y de la filosofía de la liberación de la siguiente forma:

Al igual que la filosofía de Lévinas, la filosofía de la liberación se configura como una meta-física de la alteridad, frente a la ontología de la Totalidad europea y nordatlántica. Y es una metafísica que constituye una alternativa radical a la filosofía hegemónica y pensada como única. ${ }^{3}$

El planteamiento de Dussel en particular, cuando aborda el tema del Otro, está influido por la filosofía de Emmanuel Lévinas. Dussel va a seguir en parte los planteamientos del filósofo francés, pero se desligará de él al darse cuenta que en los trabajos de Lévinas hace falta un elemento fundamental: concretar ese otro, darle un rostro; de lo contrario, ese Otro sólo será un concepto más de la Modernidad europea. La filosofía de la liberación latinoamericana, ve necesario y obligatorio afirmar que ese Otro tiene un rostro concreto: la víctima, el excluido, el marginado. Ese rostro es el que interpela y llama a hacer algo a su favor, a solidarizarse con él y a ayudarle a sentirse protagonista de su propia liberación.

Esta víctima es la que Europa ha encubierto utilizando términos optimistas, como dirá Dussel en su ética de la liberación: "La vida buena de los ricos y poderosos de Europa viene a ser la negación o la vida mala para las víctimas, los dominados". ${ }^{4}$ Dicho de otra manera, lo que Europa veía como bueno, es decir, el sometimiento y colonización de los países conquistados, como dirá Franz Hinkelammert comentando a Locke, "ellos necesitan ser civilizados", viene a ser lo que genera explotación, opresión y crimen para estos países sometidos. ${ }^{5}$

3 Beorlegui, C., Historia del pensamiento filosófico latinoamericano. Edit. Universidad de Deusto, Bilbao, 2004.

4 Cf. Dussel, E. Etica de la Liberación en la edad de la globalización y la exclusión. Ed. Trotta, Madrid, 1998

5 Hinkelammert desarrolla este planteamiento, trabajándolo como una "Inversión de los derechos humanos" y para ello recurre a los argumentos del filósofo empirista John Locke. Cf. Hinkelammert, Fr. El sujeto y la ley. El retorno del sujeto reprimido. Ed. Universidad Nacional, Heredia, 2003. Págs. 75ss. 
Después de haber planteado el argumento filosófico de este trabajo, se pasa a describir las tres situaciones en las que se refleja el encubrimiento.

\section{El colonialismo como encubrimiento del Otro en Oriente (Orientalismo) ${ }^{6}$.}

En esta primera parte se desarrolla el concepto de Orientalismo como una forma de encubrimiento de Europa hacia Oriente. Uno de los autores que visualizará este encubrimiento es Edward Said en su libro Orientalismo. En su introducción, plantea cómo Europa ha realizado un encubrimiento en su relación con Oriente. En lenguaje de Dussel, se dice lo mismo de Oriente, pero no lo otro de Oriente. Este encubrimiento se manifiesta a través de tres aspectos: la interpretación superficial, la hegemonía y la relación actual entre Estados Unidos y Oriente.

\section{a- El encubrimiento de Europa a Oriente al describirlo de manera superficial}

Para Said, Oriente es el escenario en el que Europa ha construido un imaginario que tiene que ver, especialmente, con los aspectos estrictamente exóticos, en detrimento de los elementos políticos e ideológicos. El interés de Europa en Oriente estuvo más en elementos superficiales porque era lo más atractivo que tenía Oriente; poco interesaba su forma de organización social y política, que ellos consideraban inferior e, incluso, primitiva. A la vez esta superficialidad justificó el derecho que se adjudicó Europa de adquirir riqueza y colonizar a estos países. Asia y África fueron las regiones más afectadas en este proceso.

b- El encubrimiento de Europa hacia Oriente como justificación de su poder o hegemonía

Europa, al construir su propia reflexión sobre Oriente, el orientalismo, no ha hecho más que justificar sus estructuras de dominación. En muchos de sus enfoques sobre Oriente, Europa justifica su dominio afirmando que es justo civilizar esas culturas por su inferioridad en organización política y su inferioridad a nivel cultural. Por tanto, el orientalismo es un estilo occidental, según Said, que pretende dominar, reestructurar y tener autoridad sobre Oriente; en una sola palabra orientalizar.

Además, Europa ha logrado construir sobre Oriente ciertas relaciones de poder y dominación, según Said, porque no sólo consiguió que Oriente fuera sometido, sino porque ahí se podía conseguir lo que fuera, incluso por la fuerza. Con esta forma de encubrimiento se puede sostener que Oriente es una región fácilmente sometible. Sin embargo, está claro que, como dice Said, esta región fue de complicada dominación. Eso significa que la colonización implicó en cierta forma, una reacción de resistencia de parte de los colonizados; no obstante, las armas y los recursos con los que contaba esta resistencia eran insuficientes ante el poderío armamentista de Europa.

6 Esta primera parte está basada en Said, Edward W. Orientalismo. Debolsillo, Barcelona, 2003 
Otra forma en concreto de expresar el poder y la hegemonía de Europa hacia Oriente es la identidad. Europa adquiere mayor fuerza e identidad en detrimento de Oriente y esto significa que Oriente es inferior a Europa en todos los ámbitos de su vida. Esto vuelve a demostrar cómo se justifican una serie de teorías que Europa va a construir sobre Oriente a nivel de religión, por ejemplo, afirmando que la Biblia es mejor libro que las tradiciones culturales que ellos, los orientales, tenían; que es mejor el arte y la música europea, porque su música refleja un fuerte atraso; que la filosofía europea es mucho más sólida, frente a las filosofías orientales que son menos racionales... En fin, pueden ser muchos los ejemplos, pero todos demuestran que Europa ha visto a Oriente con actitudes de superioridad y, quizá, sigue haciéndolo.

Otro rasgo que no podemos olvidar de este tipo de encubrimiento es que podemos encontrar distintos tipos de poder, de acuerdo a Said: en primer lugar, un poder político que se concreta en la imposición de una política y estado colonial. En Oriente, Europa ha impuesto su política y no ha dado apertura a la organización política propia de esos países. Incluso en algunos países los líderes que gobernaban ciertas regiones sometidas eran europeos y no habitantes de la localidad. En segundo lugar, el poder intelectual, es decir el establecimiento de ciencias predominantes propiamente europeas como la lingüística comparada, las ciencias sociales, etc. El conocimiento local no cuenta, sólo el que el país colonizador propone. La intelectualidad propia de estos países queda opacada por la intelectualidad ilustrada europea. En tercer lugar, un poder cultural, que es específicamente la imposición de una cultura, de unas costumbres, de una forma de vivir y pensar únicamente desde la perspectiva europea. Finalmente, existe también el poder moral, es decir, que las formas de manejar nuestras decisiones y actitudes van a depender también de lo que disponga la colonia europea. En este caso no cuentan los aspectos éticos de la cultura local (valores, formas de tomar decisiones, etc.).

En conclusión, esta imposición de Europa sobre Oriente manifestada en las relaciones de poder, refleja que se ha ocultado lo verídico de Oriente a favor de la justificación del dominio de Europa sobre estas naciones.

c- El encubrimiento en las relaciones entre EE. UU. y Oriente..

Para plantear este tercer aspecto de esta forma de encubrimiento, se cita otro texto de Said que dice lo siguiente:

El orientalismo proviene de un nivel de relaciones muy particulares que mantuvieron Francia y Gran Bretaña con Oriente, que hasta principios del X. XIX solo se había limitado a la India y a las tierras bíblicas. Desde el comienzo del s. XIX, 
y hasta el fin de la Segunda Guerra Mundial, Francia y Gran Bretaña dominaron Oriente; desde la segunda Guerra Mundial, Estados Unidos ha dominado Oriente y se relaciona con él del mismo modo en que Francia y Gran Bretaña lo hicieron en otra época. ${ }^{7}$

El problema de hoy es que, además de Europa como colonizador, se ha sumado a esta lista otro colonizador más: Estados Unidos. ${ }^{8}$ Los niveles de relación entre Estados Unidos y Oriente se han mantenido al mismo nivel que el de los países europeos con los países colonizados en otra época. Este nuevo imperio colonizador ha utilizado, al menos actualmente como encubrimiento, el restablecimiento del sistema democrático; este restablecimiento ha significado imponer en Oriente un estilo de gobierno acorde a los intereses estadounidenses.

\section{El colonialismo como encubrimiento del Otro en América.}

Enrique Dussel presenta cuatro términos que definen la situación de Europa con relación a América. Estos son invención, descubrimiento, conquista y colonización. El eje común de estos cuatro términos es la imposición de subjetividades europeas: el Yo europeo moderno, de las que más adelante hablará Dussel, contra el Otro de América, el indio, que prácticamente ha sido anulado en su existencia. Dussel tomará como referencia los planteamientos de Edmundo O'Gorman.

Aquí se comentarán dos conferencias de Dussel basadas en el libro "1492: el encubrimiento del otro"".

3.1. De la invención al descubrimiento del nuevo mundo.

La primera conferencia que se comentará inicia con el planteamiento de un problema: ¿Cuándo y cómo aparece en América la conciencia histórica? La respuesta sólo puede lograrse a partir de la construcción de un proceso ontológico americano, es decir, al preguntarse por el "ser americano". Para hacer este análisis, O’Gorman utiliza un enfoque heideggeriano.

Esta conferencia se divide en dos partes: la invención del ser asiático y el descubrimiento del nuevo mundo.

a. La invención del ser asiático del Nuevo Mundo

En primer lugar, Dussel habla sobre la invención del ser asiático del Nuevo Mundo. La referencia fundamental de su estudio será la experiencia de Cristóbal Colón

7 Op. Cit., p. 22-23

8 Ibid., p. 23

9 Dussel, E. 1492: el encubrimiento del rostro del Otro. Plural Edit., la Paz, 1994. 
y, adelantándose al análisis Dussel, concluirá que lo que O'Gorman plantea es que en realidad Colón no descubrió América en un sentido estrictamente ontológico. Esto quiere decir que no descubrió lo que se denominó más arriba el ser americano.

En segundo lugar, se plantea el des-cubrimiento del Nuevo Mundo, que más que descubrimiento es una forma de autointerpretación de Europa en la que pasa de ser una de las tres o cuatro partes del mundo, a considerarse el centro del mundo, en la Europa moderna.

En el primer apartado, la invención del ser asiático del Nuevo Mundo, se describe la experiencia ontológica, tal como fue vivida por Cristóbal Colón. Su mundo de la vida, utilizando el término heideggeriano, fue el de un navegante del Mediterráneo (Mare Nostrum de los romanos), en torno a cuyas aguas estaban Europa, África y Asia. Es un mundo lleno de fantasía renacentista de un mercader de Venecia; de un cristiano italo-ibérico enfrentado al mundo musulmán del norte de África y a los turcos.

Colón se da a la empresa de cruzar el Mar Océano el 3 de agosto de 1492 con un solo propósito: llegar a la India, al Asia por Occidente, para adquirir así conocimientos náuticos, para llenarse de oro, de dignidad y además, honestamente expandir la fe cristiana. Sus ideas eran las del último mercader del Mediterráneo Occidental y las del primer moderno.

Además, la experiencia de Colón no tiene comparación alguna con la experiencia de los Vikingos y los portugueses. Esa experiencia se puede interpretar como un ir viendo lo ya sabido; un ir descubriendo un lugar (geográfico, histórico y teológico) en la cosmovisión renacentista. Lo que Colón vio o quiso ver es distinto a las experiencias anteriores.

Dussel, comentando a O'Gorman, afirma que Colón impuso un ser a ese ente descubierto y es el ser asiático. Posteriormente, enfatiza cómo en sus cuatro viajes va presentando pruebas de los descubrimientos realizados. No obstante, los cuatro viajes contemplan cómo Colón, incluso, muere con la clara conciencia de haber descubierto el camino por el occidente hacia el Asia. En pocas palabras, el ser-asiático de este continente sólo existió en el imaginario de los europeos renacentistas. No obstante, con su invención pudieron seguir existiendo las Tres Partes de la Tierra (Europa, África y Asia).

Colón es considerado el primer hombre moderno, el primero que sale oficialmente de la Europa Latina, para iniciar la constitución de la experiencia existencial 
de una Europa Occidental, atlántica, centro de la historia ${ }^{10}$. Esta idea de ser el centro tiene también matices bíblico-religiosos. Este matiz consiste en afirmar que Adán y Eva son "europeos" y su mito es considerado como el origen de la europeidad y no el origen de otras culturas. América fue inventada a imagen y semejanza de Europa. En esta conferencia se entiende invención como la experiencia colombina de prestar un ser-asiático a las islas encontradas en su ruta hacia a la India. El ser-asiático es un invento que sólo existió en el imaginario, en la fantasía estética y contemplativa de los grandes navegantes del Mediterráneo. El indio desapareció como otro y fue descubierto como lo Mismo ya conocido: en-cubierto.

\section{b. El descubrimiento del Nuevo Mundo}

El término descubrimiento puede ser entendido como la experiencia a la vez estética y contemplativa, aventura explorativa y hasta científica del conocer lo nuevo, que a partir de una experiencia resistente y terca exige romper con la representación del mundo europeo como una de las "Tres partes de la Tierra". Al descubrir una "Cuarta Parte" la Europa provinciana, renacentista, mediterránea, se transforma en la Europa Centro del mundo: en la Europa moderna. De acuerdo a esta visión, si Europa es el centro, todas las otras culturas constituyen su Periferia. Y es por esto que aquí nace estricta e históricaexistencialmente la Modernidad (como concepto y no como mito), desde el 1502 aproximadamente.

Aquí se fundamenta todo en la labor de navegación, bajo la potestad portuguesa, de Américo Vespucio (Amerigo Vespucci, en italiano). Se empieza a describir la empresa de navegación que realizó para llegar a atravesar así el llamado "Sinus Magnus". No obstante, la empresa se mostraba más difícil de lo proyectado. En septiembre de 1502, Vespucci retornaba a Lisboa sin haber podido llegar al Sinus Magnus, no había encontrado el paso a la India, pero poco a poco se fue convirtiendo en el descubridor.

En el ego concreto de aquel descubridor se terminó de producir el pasaje de la Edad Media renacentista a la Edad Moderna; Colón fue inicialmente el primer moderno; Amerigo terminó el tiempo de su constitución: un Mundo Nuevo. Europa pasaba de ser una particularidad sitiada por el mundo musulmán a ser una nueva universalidad descubridora.

Para O'Gorman en su fundamento ontológico, dicha experiencia no es un descubrimiento de lo nuevo, sino simplemente el reconocimiento de una materia o potencia donde el europeo comienza a inventar su propia imagen y semejanza. América no es descubierta como algo que resiste distinta como el Otro, 
sino como la materia a donde se le proyecta lo Mismo. No es entonces la aparición del Otro, sino la proyección de lo Mismo: en-cubrimiento. Es una tesis eurocéntrica expresa y real en cuanto a hecho de dominación.

Des-cubrir, entonces, es el constatar la existencia de tierras continentales habitadas por humanos al este del Atlántico hasta entonces totalmente desconocidas por el europeo, lo cual exige abrir el horizonte ontológico de comprensión del mundo de la vida cotidiana.

A consecuencia de ello, el círculo se cierra: la Tierra había sido des-cubierta como el lugar de la Historia Mundial; por primera vez aparece una Cuarta Parte (América), que se separa de la cuarta península asiática, desde una Europa que se autointerpreta, también por primera vez como Centro del acontecer humano en general, y por lo tanto despliega su horizonte particular como horizonte universal.

El ego ha aparecido en su confrontación con el no-ego; los habitantes de las nuevas tierras descubiertas no aparecen como Otros, sino como lo Mismo a ser conquistado, colonizado modernizado, civilizado, como materia del ego moderno.

Europa ha constituido a las otras culturas, mundos, personas como ob-jeto: como lo arrojado ante sus ojos. El cubierto ha sido des-cubierto, es un ego europeizado, pero inmediatamente en-cubierto como Otro. El Otro constituido como lo Mismo. En consecuencia, esos otros son la cultura más rústica descubierta para ser civilizada por el ser europeo de la Cultura Occidental, pero en-cubierta en su Alteridad.

\subsection{De la conquista a la colonización del mundo de la vida (Lebenswelt)}

En la siguiente conferencia Dussel plantea otras dos figuras del encubrimiento, la conquista y la colonización.

\section{a- La conquista}

Dussel entiende la conquista como una figura práctica de relación PersonaPersona, como un proceso político y militar. Aquí se trata, según Dussel de la dominación de las personas, de los pueblos, de los indios. No es una theoria, sino una praxis de dominación. La conquista era considerada como una figura jurídico-militar que justificaba el triunfo y el control de los cuerpos de las personas, por tanto, era necesario pacificarlas. Dussel sostiene también que el que establece esta dominación del mundo español es un militar guerrero. Entonces, le da una categoría filosófica a la construcción del ego conquiror (yo conquistador) afirmando que 
El Conquistador es el primer hombre moderno activo, práctico, que impone su individualidad violenta a otras personas, al Otro. ${ }^{11}$

Dussel entiende la Conquista como un proceso militar, práctico, violento que incluye dialécticamente al otro como lo Mismo. El otro es negado como tal y es obligado a incorporarse a la Totalidad dominadora. El otro, desde esta perspectiva, es visto como cosa, como instrumento, como oprimido, como encomendado, como asalariado.

Es en este momento que se da la construcción de una subjetividad europea a costa de la anulación de la subjetividad india; lo Otro es anulado, minimizado, destruido. Para Dussel, la dominación más fue matanza e inorgánica ocupación que sistemático dominio.

Dussel personifica esa forma de conquista como dominio, en la figura de Hernán Cortés. Cortés tuvo una subjetividad que poco a poco se fue construyendo procesualmente: en primer lugar, es nombrado Capitán General; en segundo lugar, al empezar sus labores de conquista, es considerado como un dios para los indios, lo que le sitúa su ego de otra manera. Es una forma de ubicar la superioridad cuasi-divina del Yo europeo sobre el Otro primitivo, rústico, inferior. Dussel radicaliza más esta expresión al afirmar que este es un yo violentomilitar que codicia, que anhela riqueza, poder gloria ${ }^{12}$. Se da un eufemismo, el encuentro de dos mundos; esto se expresa en concreto en que en lugar de ser encuentro es la prepotencia de uno (el "Yo" europeo) a costa de la destrucción y anulación del Otro (el azteca).

En consecuencia, al ser considerado un "dios", hace posible que se sitúe frente al señor y emperador Moctezuma. Es un encuentro cara-a-cara, a igual, con Moctezuma. Dussel sostendrá que "Ser-Señor" sobre otro antiguo Señor (el yoconquistador) es la proto-historia de la constitución de la subjetividad, el ego cogito, como "voluntad-de-poder. Entonces, la Conquista es afirmación práctica del yo conquisto y negación del otro como otro.

\section{b- La "colonización"}

Dussel describe la "colonización" de la misma manera que la "Conquista" sólo que no ya como praxis guerrera, sino como praxis erótica y económica. Dussel dirá que "es el comienzo de la domesticación, estructuración, colonización del "modo" como aquellas gentes vivían y reproducían su vida humana. Esto traerá como consecuencia la construcción de una raza muy particular. Esta construcción de la raza se concreta en la domesticación de la vida de la india de América. Dussel utiliza el término "ego fálico" para expresar la violencia erótica del Colonizador, hacia el otro o la otra, que es negada. Esto consiste 
en que el conquistador mata al varón indio violentamente o lo reduce a la servidumbre, y se acuesta con la india (aún en presencia del varón indio), se amanceba con ellas, como se decía en el siglo XVI. ${ }^{13}$.

Es una sexualidad puramente masculina, opresora, alienante; es una dominación sexual hacia la india y respeto aparente de la mujer europea. Por ende, de esa relación violenta nace el hijo bastardo (el "mestizo", el latinoamericano, fruto del conquistador y la india) y el criollo (el blanco nacido en el mundo colonial de Indias).

En el caso del indio, a este se le explotará a través del dominio del cuerpo expresado sobre todo en el trabajo. La corporalidad india será inmolada y transformada primeramente en oro y plata. Pero lo que era oro y plata en Europa, dinero del capital naciente, era muerte y desolación en América. La corporalidad subjetiva del indio era subsumida en totalidad de un nuevo sistema económico naciente, como mano de obra gratis o barata (a esta se sumará el trabajo del esclavo africano)

\section{El encubrimiento actual: Estados Unidos y su relación con el mundo árabe.}

En la tercera parte, este escrito se centra en los planteamientos de Samuel Huntington expresados en su libro El choque de civilizaciones y la reconfiguración del nuevo orden mundial ${ }^{14}$. Huntington plantea cómo EE. UU., actualmente, ha querido encubrir su avance imperialista violento afirmando que en los países que ha invadido (Iraq, Afganistán, por ejemplo) "era necesario instaurar la democracia". No obstante, a diferencia de las otras experiencias anteriores de encubrimiento, las naciones que han sido víctimas de esta universalización política (instauración de la democracia), han opuesto, en cierta forma, una resistencia más férrea. Tal resistencia ha desembocado en ocasiones, en guerras sangrientas.

Huntington toca el problema de manera indirecta. El no habla de "encubrimiento" del Otro; no obstante, hace alusión a este problema cuando afirma que Occidente, representado actualmente no sólo por Europa sino también por Estados Unidos, ha tenido una influencia importante y a veces devastadora, para con los países de Oriente.

Por ejemplo: una de las mayores expresiones del encubrimiento actual es que Estados Unidos quiere que los países no-occidentales asuman responsablemente los valores de democracia, mercados libres, gobierno limitado, derechos humanos, 
etc., propios de occidente. No obstante, en algunas culturas no-occidentales, como la cultura musulmana, esto puede entenderse como una imposición. El encubrimiento se expresa concretamente en la frase: "Lo que para Occidente es universalismo, para el resto del mundo es imperialismo"15. Esto quiere decir que "instaurar la democracia" es la frase que encubre la política de dominio y sometimiento por parte de Estados Unidos.

Esta última frase demuestra la actualidad del colonialismo norteamericano. La razón es que, en las dos partes anteriores se ha planteado que el encubrimiento va a expresar en consecuencia, estrategias de dominio del otro y de anulación del otro. Estados Unidos, de la misma forma, quiere legitimar su expansión imperial, anulando al otro. Es repetir la expresión de Dussel: "El yo-norteamericano (ya no sólo el europeo) domina al Otro", es decir, a Oriente representado en este momento por el mundo islámico y la cultura asiática, de la que habla Huntington.

Para Occidente, especialmente para Estados Unidos (y Gran Bretaña, a veces), lo importante es defender sus propios intereses; una manera de defenderlos es utilizar una especie de imperativo moral universal formulado de la siguiente manera: los intereses de EE. UU. deben ser también intereses de la "comunidad mundial". En consecuencia, lo que se pretende es integrar (someter) las economías no-occidentales a una economía global dominadora. Occidente, en particular Estados Unidos, quiere imponer las directrices económicas a las naciones no occidentales a su antojo. Esto se puede aplicar a América latina, especialmente en los Tratados de Libre Comercio. En realidad, estos tratados expresan el dominio de las políticas comerciales de EE.UU. hacia los países de América Latina. La integración al comercio mundial sólo se logrará si todos los países aceptan las directrices comerciales de esta nación del Norte.

Huntington plantea que hay una contradicción entre la teoría occidental y su práctica. Al parecer, éstas son también formas de establecer encubrimientos. Samuel Huntington expresa lo siguiente:

Se promueve la democracia, pero no si lleva a los fundamentalistas islámicos al poder; se predica la no proliferación nuclear para Irán e Irak, pero no para Israel; el libre comercio es el elixir del crecimiento económico, pero no para la agricultura y la ganadería... ${ }^{16}$

En el fondo, este encubrimiento está generando unas relaciones conflictivas entre EE. UU. y las naciones orientales, así como para América Latina. Una de las grandes expresiones conflictivas de este dominio norteamericano fue el atentado terrorista perpetrado contra el World Trade Center, el 11 de septiembre de 2001. 
Es éticamente reprobable que se hayan perdido cerca de 3000 vidas humanas; no obstante, se puede afirmar también que este acontecimiento envió un mensaje claro a EE. UU.: no todos los países, grupos, culturas o etnias están conformes con la política exterior que ha estado proyectando este país contra las naciones de Oriente. Esto no significa que se esté de acuerdo con las prácticas que realizan los movimientos extremistas.

\section{CONCLUSIONES.}

El tema desarrollado en estos planteamientos es interesante porque se va descubriendo cómo se ha construido todo un imaginario que justifica cómo Europa y EE. UU. han querido afirmar su afán de dominio encubriendo al Otro hasta llegar al extremo de negarlo. Las tres reflexiones descritas expresan este afán de colonización de maneras muy diversas:

- En primer lugar, está claro que Occidente sólo puede referirse a Oriente autoafirmándose. Europa expresó este afán de encubrimiento y dominio de varias formas: en primer lugar, planteando que a Oriente sólo hay que conocerlo desde sus elementos exóticos, pero no desde su cultura, su política, su organización social. Esos cuatro elementos, Europa los ha impuesto en algunas culturas orientales, especialmente en la India, donde realizó una de las mayores campañas de colonización y exterminio. En segundo lugar, Europa expresó su hegemonía, sintiéndose una nación superior a las naciones conquistadas; lo más dramático de este segundo momento, es que se impuso una cultura a costa de la anulación de otra. Todas las tradiciones culturales de las regiones conquistadas quedaron en el olvido porque Europa las consideraba atrasadas. Por tanto, era necesario someter estas culturas para garantizar el avance de la sociedad y la civilización.

- En segundo lugar, las cuatro formas de encubrimiento del Otro en América propuestas por Dussel, recuerdan lo que se dice en los cursos de Estudios Sociales e Historia en la educación primaria y secundaria en El Salvador. La celebración del 12 de Octubre se ha denominado "el día de la raza" y se celebra como el día del encuentro entre dos mundos: el español y el de América. Lo que se encubre en estas celebraciones es la cuota de muerte y exterminio que generó ese "encuentro". Lo mismo que en el primer caso, todas las tradiciones culturales, religiosas, sociales, políticas, etc. quedaron anuladas a favor de la imposición de la cultura española. Por tanto, es conveniente abrir los ojos y seguir el ejemplo de algunos países latinoamericanos que han cambiado el nombre de esta celebración del 12 de octubre. Por ejemplo, Venezuela y Guatemala le han llamado "El día de la resistencia de los pueblos indígenas". Es el nombre que en lugar de "encubrir", descubre algunas de las verdaderas realidades que se sucedieron en estas regiones durante la conquista. A esto hay que añadir que muchos investigadores se encuentran en problemas cuando 
quieren fundamentar sus planteamientos en documentos históricos antiguos, ya que estos fueron anulados o quemados por la misma civilización española o los enfoques que sobre el descubrimiento se encuentran sólo están desde la perspectiva de un escritor español o europeo.

- En tercer lugar, el encubrimiento actual se expresa en las relaciones entre EE. UU. y el mundo islámico. Para mí, lo más doloroso de este avance imperial de EE. UU., que tiene como fin establecer el valor universal de la democracia, como dirá Huntington, es que en países como Irak, se impuso la "democracia" a costa de anular tradiciones culturales milenarias. En los cursos de formación universitaria se les recuerda a los estudiantes el valor de la cultura mesopotámica, por ejemplo; no obstante, se hace difícil hablar de culturas milenarias, ahora que los monumentos, casas, templos antiguos, etc. fueron destruidos por una guerra que tuvo como encubrimiento el valor de la “democracia” ('vamos a instaurar un gobierno democrático', dirá EE. UU.) y cuyo interés fue más bien asegurar la economía internacional del petróleo que el valor de la democracia.

- En cuarto lugar, se quiere destacar aquí que no sólo se imponen culturas, sino también subjetividades. El sujeto-individuo de Europa se impone sobre el sujeto latinoamericano. Dicho de otra manera, el sujeto victimario europeo, se impone al sujeto víctima latinoamericano. Haber descubierto esto debe más bien dar una esperanza: la necesidad de construir una subjetividad propia de América latina. Ya las filosofías de la liberación se han planteado el problema y han llegado a la conclusión que el sujeto europeo es más conceptual; el sujeto latinoamericano es más concreto, más dinámico, más social. Enrique Dussel, Franz Hinkelammert e Ignacio Ellacuría, entre otros, se dieron a esta tarea de proponer una alternativa distinta a la subjetividad europea. Esto puede considerarse un aporte valioso para la filosofía latinoamericana. El sujeto que proponen estos autores no es un agente pasivo, sino activo, transformador de la historia y forjador de sus propios procesos históricos. Este sujeto no es solipsista, sino que es comunidad, es diálogo, es participación y apertura al Otro, dándole la identidad y el lugar que éste se merece. Este sujeto se expresa con toda claridad en las víctimas concretadas en rostros de campesinos, obreros, asalariados, etc. que siempre han sido vistos como lo sobrante de la historia.

- Finalmente, tiene que haber una actitud más crítica hacia estas situaciones. La sociedad salvadoreña tiene que abrir los ojos ante estas siniestras construcciones políticas y sociales propias del sistema dominador; la sociedad tiene que estar clara que estas construcciones sólo tienen como objetivo mantener en el poder a los que ya están. Es urgente, como dirá Arturo Escobar ${ }^{17}$, recuperar el lugar, lo

17 Escobar, Arturo. El lugar de la naturaleza y la naturaleza del lugar: ¿globalización o postdesarrollo?. En, Lander, Edgardo (Compilador). La colonialidad del saber: eurocentrismo y ciencias sociales. Buenos aires, Clacso, 2005 
local, para poder decir algo ante estas injusticias que se cometen. Es necesario que sobresalgan líderes, pero también organizaciones sociales y comunitarias locales que manifiesten su presencia y puedan decir algo a la sociedad actual. Este es quizá una de las mejores armas para enfrentar el encubrimiento que propone el sistema dominador.

\section{BIBLIOGRAFÍA}

1. Beorlegui, C., Historia del pensamiento filosófico latinoamericano. Universidad de Deusto, Bilbao, 2004.

2. Dussel, E., El encubrimiento del Otro. Plural, La Paz, 1992.

3. Dussel, E., - Etica de la liberación en la edad de la globalización y la exclusión. Trotta, Madrid, 1998.

4. Hinkelammert, F., El sujeto y la ley. El retorno del sujeto reprimido. Universidad Nacional, Heredia, 2003

5. Huntington, S., El choque de civilizaciones y la reconfiguración del orden mundial, Paidós, Barcelona, 1996.

6. Lander, E. (compilador)., La colonialidad del saber: eurocentrismo y ciencias sociales, Clacso, Buenos Aires, 2000.

7. Said, E., Orientalismo, Debolsillo, Barcelona, 2003. 